\title{
Effect of COVID-19 pandemic on the lifestyle and glycemic control in patients with type 1 diabetes: A retrospective cohort study
}

\section{Yukako Hosomi}

Kyoto Prefectural University of Medicine

\section{Chihiro Munekawa}

Kyoto Prefectural University of Medicine

Yoshitaka Hashimoto ( $\nabla$ y-hashi@koto.kpu-m.ac.jp )

Kyoto Prefectural University of Medicine https://orcid.org/0000-0002-8794-0550

\section{Takuro Okamura}

Kyoto Prefectural University of Medicine

Fuyuko Takahashi

Kyoto Prefectural University of Medicine

\section{Rena Kawano}

Kyoto Prefectural University of Medicine

\section{Hanako Nakajima}

Kyoto Prefectural University of Medicine

\section{Saori Majima}

Kyoto Prefectural University of Medicine

Takafumi Senmaru

Kyoto Prefectural University of Medicine

Naoko Nakanishi

Kyoto Prefectural University of Medicine

\section{Emi Ushigome}

Kyoto Prefectural University of Medicine

\section{Masahide Hamaguchi}

Kyoto Prefectural University of Medicine

\section{Masahiro Yamazaki}

Kyoto Prefectural University of Medicine

Michiaki Fukui

Kyoto Prefectural University of Medicine 
Keywords: COVID-19, Infection, Stress, Lifestyles, Type 1 diabetes

Posted Date: September 29th, 2020

DOI: https://doi.org/10.21203/rs.3.rs-83364/v1

License: (c) (1) This work is licensed under a Creative Commons Attribution 4.0 International License. Read Full License

Version of Record: A version of this preprint was published at Diabetology International on April 19th, 2021. See the published version at https://doi.org/10.1007/s13340-021-00507-4. 


\section{Abstract}

Background: To investigate the acute effects of the coronavirus disease 2019 (COVID-19) on the lifestyle and metabolic parameters in patients with type 1 diabetes mellites (T1DM).

Methods: This retrospective cohort study induced 34 patients who received our hospital from April 16 to May 1, 2020. Data regarding stress levels, sleep time, exercise, and total diet, snack, and prepared food intake were obtained from the questionnaires. To evaluate the pandemic effect on the changes in the body weight or $\mathrm{HbA} 1 \mathrm{c}$ levels, we evaluated those differences of the values at the time the questionnaire was administered to those noted 3 months ago and those differences of 12 months ago and 15 months ago using paired $t$ test.

Results: Increased stress levels and decreased exercise levels were observed in approximately $60 \%$, and $50 \%$ of the participants, during the COVID-19 pandemic. There was a negative correlation between stress and exercise $(r=-0.407, p=0.021)$. Decreased sleep duration were associated with increased body weight $(r=-0.40, p=0.042)$. Furthermore, compared with 1 years ago, $\mathrm{HbA} 1 \mathrm{c}$ was become worse (this year 0.12 $[0.33] \%$ in this year vs. $-0.09[0.39] \%$ in 1 years ago, $p=0.027)$.

Conclusions: Many patients experienced stress and decreased exercise due to the COVID-19 pandemic. The glycemic control of patients with T1DM was worse than last year. Given that the pandemic is ongoing, we should pay more attention to the management of stress and lifestyle factors in patients with T1DM.

\section{Background}

Coronaviruses (CoV) is one of the common viruses of respiratory infections in humans [1]. Generally, human CoV infections are not severe; however, two major outbreaks of CoV infection have occurred in the past, namely severe acute respiratory syndrome coronavirus (SARS-CoV) infection in 2002-2003 and Middle East respiratory syndrome coronavirus (MERS-CoV) infection in 2012 [2-4]. Nowadays, a new coronavirus, SARS-CoV-2, was recognized as the pathogen causing CoV disease COVID-19 in Wuhan, China in December 2019 [5]. On March 11, 2020, the World Health Organization declared COVID-19 a pandemic [6].

European countries have significantly curbed public life to halt the spread of COVID-19. In Japan, a state of emergency, with request-based measures of encouraging the populace to remain at home and businesses to limit operations, was declared on April 7, 2020. Therefore, the Japanese are also becoming more restrictive in their behavior. Infectious disease outbreaks, including COVID-19, are associated with increasing of stress levels of general population [7]. Previous studies showed that disasters were associated with increased stress and worse glycemic control in patients with type 1 diabetes mellitus (T1DM) $[8,9]$. 
Patients with diabetes mellitus are more likely to infected by COVID-19 and are at a higher risk of mortality $[10,11]$. Although patients with diabetes mellitus should be careful to avoid COVID-19 infection, there is a possibility that forcing these patients to restrict their life leads to worsen their glucose control. However, little is known about the effect of the COVID-19 pandemic on the glycemic control of patients with T1DM [12,13]. Therefore, this retrospective cohort study investigated the effects of the COVID-19 pandemic on the glycemic control of patients with T1DM and the effect of COVID-19 pandemic on change of stress and lifestyles.

\section{Methods}

\section{Study Patients}

We are performing an ongoing opt-out survey among the patients with diabetes mellitus to clarify the natural history of the patients with diabetes mellitus. This study was approved by the ethics committee of Kyoto Prefectural University of Medicine (KPUM) (ERB-C-1297). In this retrospective cohort study, a questionnaire was administered to the patients with T1DM who visited a clinic at the Department of Endocrinology and Metabolism, KPUM from April 16 to May 1, 2020. Patients, whose data were incomplete, were excluded.

\section{Data collection and measurements}

Type 1 diabetes mellitus was diagnosed by the Report of the Expert Committee on the Diagnosis and Classification of Diabetes Mellitus [14]. Insulin treatment, such as multiple daily injections (MDI) and continuous subcutaneous insulin infusion (CSII) were checked from medical record. According to the selfadministered questionnaire, the patients were classified as a non-, past-, or current smoker and patients who regularly played any type of sport for more than once per week, before COVID-19 pandemic, were defined as regular exercisers. Nephropathy was defined according to the report of the Joint Committee on Diabetic Nephropathy [15]. The criteria for diabetic neuropathy suggested by the Diagnostic Neuropathy Study Group was used for neuropathy [16]. Retinopathy was classified, as no diabetic-retinopathy (NDR), simple diabetic-retinopathy (SDR), and proliferative diabetic retinopathy (PDR), which included preproliferative retinopathy. Data regarding the body weight and $\mathrm{HbA} 1 \mathrm{c}$ levels at the time the questionnaire was administered and the values noted 3 months ago, 12 months ago, and 15 months ago were obtained from medical records. The difference between the values corresponding to at the time the questionnaire and 3 months ago was calculated as the change in the body weight or HbA1c levels. In addition, the difference between the values corresponding to 12 months ago and 15 months ago was calculated as the change in the body weight or $\mathrm{HbA} 1 \mathrm{c}$ levels of 1 years ago. 
The questionnaire consisted of 6 short questions regarding stress and lifestyle factors (Supplemental Table). A visual analog scale (VAS; $0=$ considerably reduced, $5=$ no change, and $10=$ considerably increased) was used for all questions and patients were asked to score how their stress levels, sleep time, exercise levels, and total diet, snack, and prepared food intakes have changed due to the COVID-19 pandemic. Based on the patient's VAS scores, we further classified them as meeting or not meeting the following categories: increased stress (VAS $\geq 6$ ), shortened sleep time (VAS $\leq 4)$ ), decreased exercise (VAS $\leq 4)$, increased total diet intake (VAS $\geq 6$ ), increased snack consumption (VAS $\geq 6$ ), and increased prepared food intake (VAS $\geq 6$ ).

\section{Statistical analysis}

The JMP version 13.2 software (SAS Institute Inc., Cary, NC) was used for statistical analyses and $p$ values $<0.05$ were considered statistically significant. The mean or frequency of potential confounding variables was calculated. The continuous and categorical variables were presented as the means ( \pm standard deviations) and absolute numbers, respectively. The differences in the change in body weight or $\mathrm{HbA} 1 \mathrm{c}$ levels and the change in the body weight or $\mathrm{HbA} 1 \mathrm{c}$ levels of 1 years ago were evaluated using the paired t-test.

\section{Results}

In this study, among 564 patients who were scheduled to visit our department, 87 patients received telemedicine and 127 patients did not visit. Among 350 patients who visited our department, 34 patients had T1DM (Figure 1).

The clinical characteristics of the study patients are shown in Table 1. The mean age and duration of diabetes of the study patients were $59.1( \pm 16.0)$ years and $14.5( \pm 16.0)$ years, and 31 patients received $\mathrm{MDI}$ and 3 patients received CSII. Increased stress levels and decreased exercise levels were observed $59.3 \%$ (19/32), and 50\% (16/32) of the participants during the COVID-19 pandemic.

The results of correlations of the change in stress and lifestyle factors during the COVID-19 pandemic is shown in Table 2. There was a negative correlation between exercise levels and stress or snack consumption and there was a positive correlation between snack consumption and prepared food intake.

Furthermore, compared with 1 years ago, $\mathrm{HbA} 1 \mathrm{c}$ was become worse in this year (this year 0.12 [0.33] \% in this year vs.-0.09 [0.39] \% in 1 years ago, $p=0.027$ ) (Table 3 and Figure 2).

\section{Discussion}

This study investigated the acute influence of the COVID-19 pandemic on the lifestyle of patients with T1DM. Based on our findings, patients with T1DM reported increased stress and decreased their exercise 
levels from the COVID-19 pandemic. Furthermore, change of glycemic control for 3 months of patients with T1DM was worse than last year.

Recent studies revealed that the COVID-19 pandemic is associated with increased stress in general populations [7]. External stress may lead to less physical activity $[17,18]$. Stress can also affect metabolic parameters in patients with diabetes mellitus $[19,20]$. In fact, previous studies showed that earthquakes were associated with increased stress and worse glycemic control in patients with T1DM [8,9]. Unlike these previous disasters, the COVID-19 pandemic is ongoing and there are concerns that the impact on patients with diabetes mellitus will continue or become worse. It has been reported that high glucose levels are associated with increased mortality in COVID-19 infection [10,11]. Therefore, we should pay attention to glycemic control of patients with T1DM.

In this study change of glycemic control for 3 months of patients with T1DM was worse than last year. A previous study revealed that there is no negative effect of lockdown due to COVID-19 pandemic on glycemic control in people with T1DM $[12,20,21]$. These studies also showed that the reason why there is no negative effect of lockdown due to COVID-19 might be because that many patients with T1DM don't have to work due to lockdown. Thus, there is a possibility that many of the participants in this study were elderly and thus they did not have job and were only have negative aspect, such as reducing exercise and increasing stress.

There are several limitations of this study. First, the sample size was relatively small, and the participants were limited to a single center. In addition, this study only included the patients who visited our department in the period of COVID-19 pandemic. Therefore, the data of patients who did not visit were not included. There is a possibility that patients who did not visit our department experienced more stress or changes in lifestyle and, therefore, poor glycemic control. Second, the questionnaire of this study was subjective and did not include quantitative evaluation. However, under the pandemic situation, the decreased contact time is essential to reduce the risk of disease transmission. Therefore, we only asked the patients simple and a minimal number of questions. Third, we did not have a data of self-monitoring of blood glucose and/or flash glucose monitoring. Fourth, we did not have data of change the dosage of insulin, although patients with T1DM are likely to change the dosage of insulin on their own. However, despite the possibility of self-titration, the glycemic control became worse, compared to the last year. Furthermore, we Lastly, this study included only Japanese patients; therefore, it is not clear whether our findings can be generalized to the populations of other countries.

\section{Conclusion}

In conclusion, many patients with T1DM reported increased stress levels and changes in lifestyle factors, especially exercise, during the COVID-19 pandemic. Furthermore, the glycemic control of patients with type 1 diabetes mellitus was worse than last year. Given that the pandemic is ongoing, we should pay more attention to the management of stress and lifestyle factors in patients with type 1 diabetes mellitus to prevent the worsening of their glycemic control. 


\section{Declarations}

Ethics approval and consent to participate

This study was approved by the ethics committee of Kyoto Prefectural University of Medicine (KPUM) (ERB-C-1297). This study was opt-out survey and opt-out survey was approved by the ethics committee.

Consent to publication: Not applicable.

Availability of data and materials: The datasets used and/or analyzed during the current study are available from the corresponding author on reasonable request. We affirmed that the manuscript is an honest, accurate, and transparent account of the study being reported; that no important aspects of the study have been omitted; and that any discrepancies from the study as originally planned.

Competing interests: All authors have completed the ICMJE uniform disclosure. Dr. Hashimoto reports grants from Asahi Kasei Pharma and personal fees from Mitsubishi Tanabe Pharma Corp., Novo Nordisk Pharma Ltd., Sanofi K.K., and Daiichi Sankyo Co. Ltd. outside the submitted work. Dr. Ushigome received grant support from the Astellas Foundation for Research on Metabolic Disorders and the Japanese Study Group for Physiology and Management of Blood Pressure, donated fund Laboratory of Diabetes therapeutics is an endowment department, supported with an unrestricted grant from Ono Pharma. Co., Ltd., and received personal fees from MSD K.K., Daiichi Sankyo Co. Ltd., AstraZeneca plc, Kyowa Kirin Co. Ltd., Astellas Pharma Inc., Mitsubishi Tanabe Pharma Corp., Kowa Pharma Co. Ltd., Sumitomo Dainippon Pharma Co. Ltd., Novo Nordisk Pharma Ltd., Taisho Toyama Pharma Co., Ltd., Takeda Pharma Co., Ltd., and Nippon Boehringer Ingelheim Co. Ltd. outside the submitted work. Dr. Hamaguchi reports grants from Takeda Pharma Co. Ltd, Sanofi K.K., Mitsubishi Tanabe Pharma Corp., Asahi Kasei Pharma, Sumitomo Dainippon Pharma Co. Ltd., Kyowa Kirin Co. Ltd., Daiichi Sankyo Co. Ltd., Astellas Pharma Inc., Novo Nordisk Pharma Ltd., Nippon Boehringer Ingelheim Co. Ltd., and Eli Lilly Japan K.K., outside the submitted work. Dr. Yamazaki reports personal fees from MSD K.K., Takeda Pharma Co. Ltd, Daiichi Sankyo Co. Ltd., Kowa Pharma Co. Ltd., AstraZeneca plc., Kyowa Kirin Co. Ltd., Sumitomo Dainippon Pharma Co. Ltd., Kowa Pharma Co. Ltd., and Ono Phama Co., Ltd. outside the submitted work. Prof. Fukui received grants from Takeda Pharma Co. Ltd., Sanofi K.K., Kissei Phama Co. Ltd., Mitsubishi Tanabe Pharma Corp, Astellas Pharma Inc., Nippon Boehringer Ingelheim Co. Ltd., Daiichi Sankyo Co. Ltd., MSD K.K., Sanwa Kagagu Kenkyusho CO., LtD., Kowa Pharma Co. Ltd., Kyowa Kirin Co., Ltd., Sumitomo Dainippon Pharma Co., Ltd., Novo Nordisk Pharma Ltd., Ono Pharma Co. Ltd., Eli Lilly Japan K.K., Taisho Pharma Co., Ltd., Tejin Pharma LtD., Nippon Chemiphar Co., Ltd., Johnson \& Johnson k.k. Medical Co., Abbott japan Co. Ltd., and Terumo Corp., and received honoraria from Teijin Pharma Ltd., Arkray Inc., Kissei Pharma Co., Ltd., Novo Nordisk Pharma Ltd., Mitsubishi Tanabe Pharma Corp., Sanofi K.K., Takeda Pharma Co. Ltd., Astellas Pharma Inc., MSD K.K., Kyowa Kirin Co. Ltd., Sumitomo Dainippon Pharma Co. Ltd., Daiichi Sankyo Co. Ltd., Kowa Pharma Co. Ltd., Ono Pharma Co. Ltd., Sanwa Kagaku Kenkyusho Co. Ltd., Nippon Boehringer Ingelheim Co., Ltd., Taisho Pharma Co., Ltd., Bayer Yakuhin, Ltd., AstraZeneca K.K., Mochida Pharma Co. Ltd., Abbott japan Co. Ltd., Eli Lilly Japan K.K., Medtronic Japan Co. Ltd., and Nipro Corp. outside the submitted work. The other authors have nothing to disclose. 
Funding: None.

Authors' Contributions: C.M. and Y.Ho. obtained and analyzed data and wrote manuscript. These authors equally contributed to this work. Y.Ha. planned, and designed the work, obtained, analyzed and interpreted data and contributed to discussion. T.O. analyzed and interpreted data and contributed to discussion. F.T., R.K., H.N., S.M., T.S., N.N., E.U., M.H., and M.Y. obtained data and contributed to discussion. M.F. contributed to the conception of the work, obtained, and interpreted data and contributed to discussion. All authors checked the final version, and agree to be responsibility for the work to ensure that any questions related to the accuracy or completeness of any of the work are appropriately investigated and resolved. Corresponding author, Yoshitaka Hashimoto, takes full responsibility for the work and publish the manuscript.

Acknowledgments: None

\section{References}

1. Cui J, Li F, Shi ZL (2019) Origin and evolution of pathogenic coronaviruses. Nat Rev Microbiol 17:181192.

2. Song Z, Xu Y, Bao L, Zhang L, Yu P, et al. (2019) From SARS to MERS, Thrusting Coronaviruses into the Spotlight. Viruses 11:59.

3. Drosten C, Günther S, Preiser W, van der Werf S, Brodt HR, et al. (2003) Identification of a novel coronavirus in patients with severe acute respiratory syndrome. N Engl J Med 348:1967-1976.

4. Zaki AM, van Boheemen S, Bestebroer TM, Osterhaus AD, Fouchier RA (2012) Isolation of a novel coronavirus from a man with pneumonia in Saudi Arabia. N Engl J Med 367:1814-1820.

5. Huang C, Wang Y, Li X, Ren L, Zhao J, et al. (2020) Clinical features of patients infected with 2019 novel coronavirus in Wuhan, China. Lancet 395:497-506.

6. World Health Organization. Rolling updates on coronavirus disease (COVID-19) 2020. Available from: https://www.who.int/emergencies/diseases/novel-coronavirus-2019/events-as-they-happen Last access 1/May/2020

7. Rajkumar RP (2020) COVID-19 and mental health: A review of the existing literature. Asian J Psychiatr 52:102066.

8. Kamoi K, Tanaka M, Ikarashi T, Miyakoshi M (2006) Effect of the 2004 Mid Niigata Prefecture earthquake on glycemic control in type 1 diabetic patients. Diabetes Res Clin Pract 74:141-147. 9. Sengül A, Ozer E, Salman S, Salman F, Sağlam Z, et al. (2004) Lessons learnt from influences of the Marmara earthquake on glycemic control and quality of life in people with type 1 diabetes. Endocr $J$ 51:407-414.

10. Zhu L, She ZG, Cheng X, Qin JJ, Zhang XJ, et al. (2020) Association of Blood Glucose Control and Outcomes in Patients with COVID-19 and Pre-existing Type 2 Diabetes. Cell Metab 31:1068-1077.e3. 11. Yang X, Yu Y, Xu J, Shu H, Xia J, et al. (2020) Clinical course and outcomes of critically ill patients with SARS-CoV-2 pneumonia in Wuhan, China: a single-centered, retrospective, observational study. Lancet Respir Med 8:475-481. 
12. Bonora BM, Boscari F, Avogaro A, Bruttomesso D, Fadini GP (2020) Glycaemic Control Among People with Type 1 Diabetes During Lockdown for the SARS-CoV-2 Outbreak in Italy. Diabetes Ther 1-11.

13. Tornese G, Ceconi V, Monasta L, Carletti C, Faleschini E, Barbi E (2020) Glycemic Control in Type 1 Diabetes Mellitus During COVID-19 Quarantine and the Role of In-Home Physical Activity. Diabetes Technol Ther 22:462-467.

14. American Diabetes Association (2012) Diagnosis and Classification of Diabetes Mellitus. Diabetes Care 35 Suppl 1:S64-71.

15. Haneda M, Utsunomiya K, Koya D, Babazono T, Moriya T, et al. (2015) A new Classification of Diabetic Nephropathy 2014: a report from Joint Committee on Diabetic Nephropathy. J Diabetes Investig 6:242246.

16. Yasuda H, Sanada M, Kitada K, Terashima T, Kim H, et al. (2007) Rationale and usefulness of newly devised abbreviated diagnostic criteria and staging for diabetic polyneuropathy. Diabetes Res Clin Pract 77 Suppl 1:S178-S183.

18. Stults-Kolehmainen MA, Sinha R (2014) The effects of stress on physical activity and exercise. Sports Med 44:81-121.

19. Lin EH, Katon W, Von Korff M, Rutter C, Simon GE, et al. (2004) Relationship of depression and diabetes self-care, medication adherence, and preventive care. Diabetes Care 27:2154-2160.

20. Lloyd C, Smith J, Weinger K (2005) Stress and diabetes: A review of the links. Diabetes Spectrum 18:121-127.

21. Mesa A, Viñals C, Pueyo I 1st, et al. The impact of strict COVID-19 lockdown in Spain on glycemic profiles in patients with type 1 Diabetes prone to hypoglycemia using standalone continuous glucose monitoring [published online ahead of print, 2020 Jul 30]. Diabetes Res Clin Pract. 2020;108354. doi:10.1016/j.diabres.2020.108354

22. Fernández E, Cortazar A, Bellido V. Impact of COVID-19 lockdown on glycemic control in patients with type 1 diabetes [published online ahead of print, 2020 Jul 22]. Diabetes Res Clin Pract. 2020;166:108348. doi:10.1016/j.diabres.2020.108348

\section{Tables}

Table 1. Clinical characteristics of the study participants 


\begin{tabular}{|ll|}
\hline N & 34 \\
\hline Age (year) & $59.1(16.0)$ \\
\hline Sex (men/ women) & $11 / 23$ \\
\hline Duration of diabetes (year) & $14.5(8.0)$ \\
\hline Smoking (non-/ past-/ current smoker) & $25 / 3 / 6$ \\
\hline Exercise habit (no/ yes) & $20 / 14$ \\
\hline Nephropathy stage (1/ 2/ 3/ 4/ 5) & $22 / 8 / 1 / 1 / 1$ \\
\hline Neuropathy (no/ yes) & $24 / 9$ \\
\hline Retinopathy (NDR/ SDR/ PDR) & $24 / 2 / 7$ \\
\hline Treatment (MDI / CSII) & $31 / 3$ \\
\hline Questionnaires (n = 32) & \\
\hline Feel stress & $6.7(2.1)$ \\
\hline Increasing of stress (no/ yes) & $13 / 19$ \\
\hline Sleep time & $4.4(1.4)$ \\
\hline Shorten sleep time (no/ yes) & $23 / 9$ \\
\hline Exercise & $3.5(2.2)$ \\
\hline Decreasing of exercise (no/yes) & $16 / 16$ \\
\hline Total diet intake & $5.1(1.4)$ \\
\hline Increasing of total diet intake (no/ yes) & $26 / 6$ \\
\hline Snack consumption & $5.0(1.9)$ \\
\hline Increasing of snack consumption (no/ yes) & $22 / 10$ \\
\hline Prepared food intake & $26 / 6$ \\
\hline Increasing of prepared food intake (no/ yes) & \\
\hline
\end{tabular}

NDR, non-diabetic retinopathy; SDR; simple diabetic retinopathy; PDR, proliferative diabetic retinopathy; MDI, multiple daily injections; CSII, continuous subcutaneous insulin infusion. All items of the change of stress and lifestyles factors were evaluated by used visual analog scale. $0=$ considerably reduced, $5=$ no change, $10=$ considerably increased.

Data are presented as the means ( \pm standard deviations) and absolute numbers. 
Table 2. The correlations of the change of stress and lifestyles factors

\begin{tabular}{|c|c|c|c|c|c|c|}
\hline & Stress & $\begin{array}{l}\text { Sleep } \\
\text { time }\end{array}$ & Exercise & $\begin{array}{l}\text { Total diet } \\
\text { intake }\end{array}$ & $\begin{array}{l}\text { Snack } \\
\text { consumption }\end{array}$ & $\begin{array}{l}\text { Prepared food } \\
\text { intake }\end{array}$ \\
\hline Stress & - & - & - & - & - & - \\
\hline \multirow[t]{2}{*}{ Sleep time } & $\begin{array}{l}r= \\
-0.152\end{array}$ & - & - & - & - & - \\
\hline & $\begin{array}{l}p= \\
0.404\end{array}$ & & & & & \\
\hline \multirow[t]{2}{*}{ Exercise } & $\begin{array}{l}r= \\
-0.407\end{array}$ & $\begin{array}{l}r= \\
0.140\end{array}$ & - & - & - & - \\
\hline & $\begin{array}{l}p= \\
0.021\end{array}$ & $\begin{array}{l}p= \\
0.445\end{array}$ & & & & \\
\hline \multirow[t]{2}{*}{$\begin{array}{l}\text { Total diet } \\
\text { intake }\end{array}$} & $\begin{array}{l}r= \\
0.146\end{array}$ & $\begin{array}{l}r= \\
0.029\end{array}$ & $\begin{array}{l}r= \\
-0.151\end{array}$ & - & - & - \\
\hline & $\begin{array}{l}p= \\
0.425\end{array}$ & $\begin{array}{l}p= \\
0.875\end{array}$ & $\begin{array}{l}p= \\
0.410\end{array}$ & & & \\
\hline \multirow[t]{2}{*}{$\begin{array}{l}\text { Snack } \\
\text { consumption }\end{array}$} & $\begin{array}{l}r= \\
0.161\end{array}$ & $\begin{array}{l}r= \\
0.176\end{array}$ & $\begin{array}{l}r= \\
-0.365\end{array}$ & \multirow{2}{*}{$\begin{array}{l}r=0.317 \\
p=0.077\end{array}$} & - & - \\
\hline & $\begin{array}{l}p= \\
0.379\end{array}$ & $\begin{array}{l}p= \\
0.334\end{array}$ & $\begin{array}{l}p= \\
0.040\end{array}$ & & & \\
\hline \multirow{2}{*}{$\begin{array}{l}\text { Prepared food } \\
\text { intake }\end{array}$} & $\begin{array}{l}r= \\
0110\end{array}$ & $\begin{array}{l}r= \\
0278\end{array}$ & $\begin{array}{l}r= \\
-0.057\end{array}$ & \multirow{2}{*}{$\begin{array}{l}r=-0.181 \\
p=0.320\end{array}$} & $r=0.393$ & \multirow[t]{2}{*}{-} \\
\hline & $\begin{array}{l}p= \\
0.548\end{array}$ & $\begin{array}{l}p= \\
0.124\end{array}$ & $\begin{array}{l}p= \\
0.758\end{array}$ & & $p=0.026$ & \\
\hline
\end{tabular}

Pearson's correlation coefficient was performed to investigate the correlations. All items were evaluated by used visual analog scale. $0=$ considerably reduced, $5=$ no change, $10=$ considerably increased.

Table 3. Change of body weight or HbA1c 


\begin{tabular}{|lllllll|}
\hline \multicolumn{3}{|c}{ This year } & \multicolumn{5}{c|}{ One year ago } \\
& $\begin{array}{l}\text { 3 months } \\
\text { ago }\end{array}$ & Baseline & Difference & $\begin{array}{l}15 \text { months } \\
\text { ago }\end{array}$ & $\begin{array}{l}12 \text { months } \\
\text { ago }\end{array}$ & Difference \\
\hline HbA1c $(n=28)$ & $7.7(0.9)$ & $7.8(0.9)$ & $\begin{array}{l}0.12 \\
(0.33)\end{array}$ & $7.5(0.9)$ & $7.4(1.0)$ & -0.09 \\
\hline $\begin{array}{l}\text { Body weight }(n \\
=19)\end{array}$ & $60.0(13,2)$ & $\begin{array}{l}60.2 \\
(13.4)\end{array}$ & $\begin{array}{l}0.16 \\
(0.97)\end{array}$ & $58.9(13.2)$ & $59.4(13.0)$ & 0.47 \\
\hline
\end{tabular}

\section{Figures}

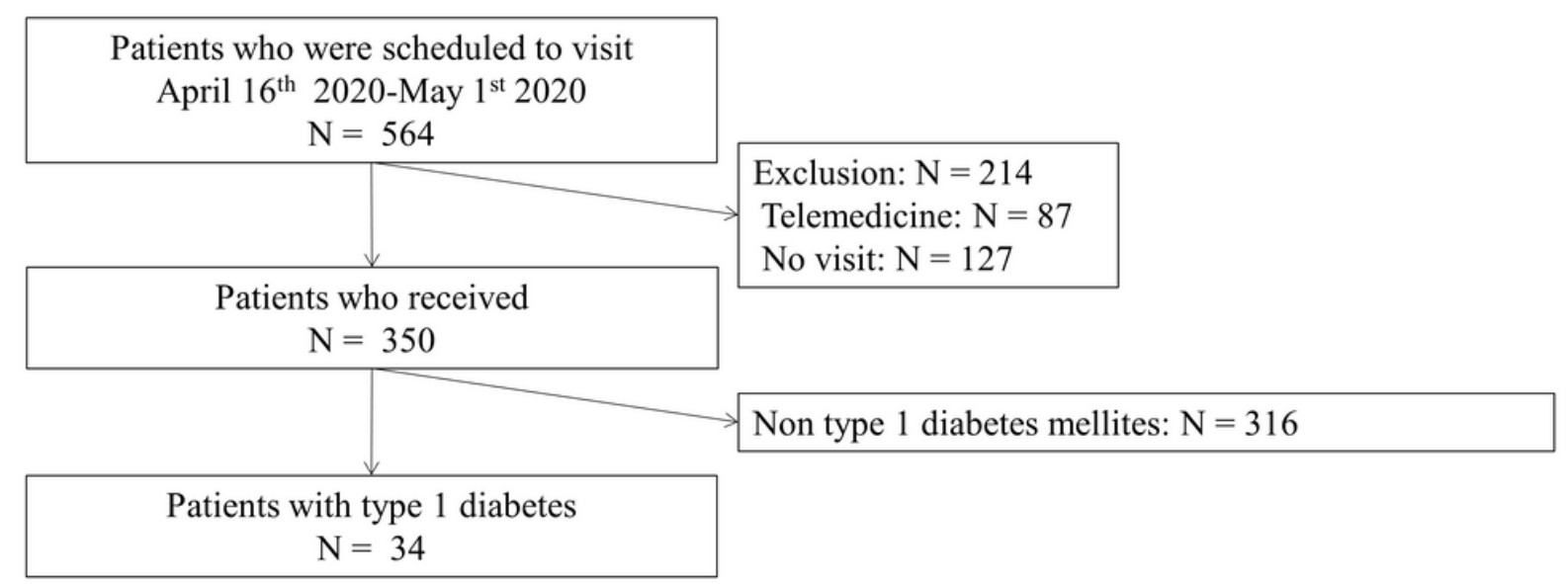

\section{Figure 1}

Inclusion and exclusion flow 
(a) Change of body weight $(n=19)$

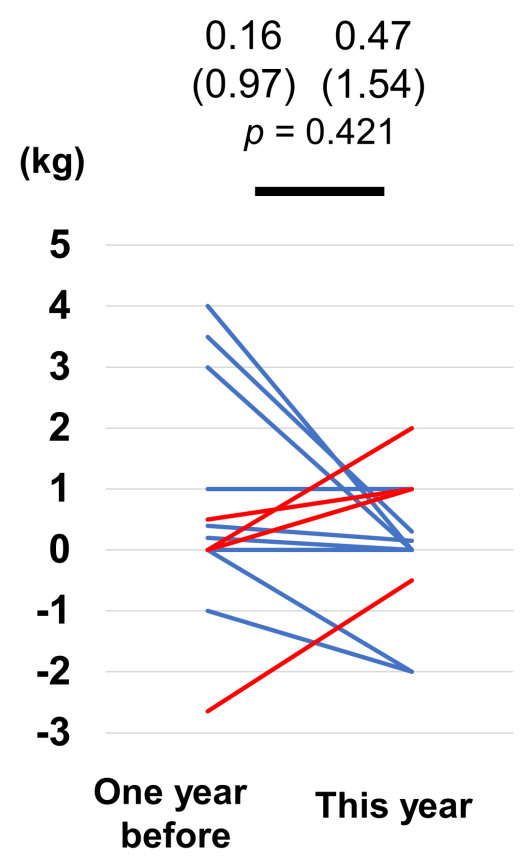

(b) Change of $\mathrm{HbA1c}(\mathbf{n}=\mathbf{2 8})$
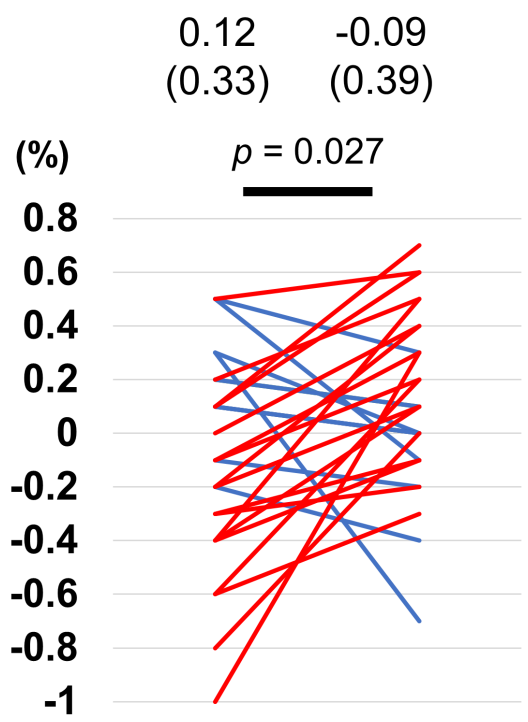

$-1.2$

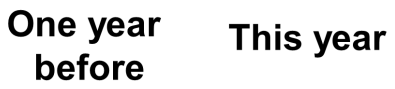

Figure 2

Difference of change of body weight or $\mathrm{HbA} 1 \mathrm{c}$ Paired $\mathrm{t}$ tests were performed to evaluate the difference. (A) Difference of change of body weight Red lines represent the case of increase the body weight due to COVID-19 pandemic. Blue lines represent the case of decrease the body weight due to COVID-19 pandemic. (B) Difference of change of HbA1c Red lines represent the case of increase the HbA1c due to COVID-19 pandemic. Blue lines represent the case of decrease the HbA1c due to COVID-19 pandemic.

\section{Supplementary Files}

This is a list of supplementary files associated with this preprint. Click to download.

- questionnaire.docx 